Article

\title{
A Bibliographic and Visual Exploration of the Historic Impact of Soft Systems Methodology on Academic Research and Theory
}

\author{
Scott Warren ${ }^{1, *(\mathbb{D}}$, Brian Sauser ${ }^{2}(\mathbb{D})$ and David Nowicki ${ }^{3}$ \\ 1 Department of Learning Technologies, University of North Texas, Denton, TX 76203, USA \\ 2 Jim McNatt Institute for Logistics Research, University of North Texas, Denton, TX 76203, USA; \\ brian.sauser@unt.edu \\ 3 Department of Marketing, Logistics, and Operations Management, University of North Texas, Denton, \\ TX 76203, USA; david.nowicki@unt.edu \\ * Correspondence: scott.warren@unt.edu; Tel.: +1-940-765-2799
}

Received: 12 December 2018; Accepted: 7 February 2019; Published: 13 February 2019

check for updates

\begin{abstract}
Soft systems methodology (SSM), an analytic method commonly employed in engineering and business research, produces models focused on human activities and relevant structures used to explain complex, engineered systems. The original version of SSM involves seven stages; five address real-world aspects and observable data, while two stages leverage a systems thinking viewpoint. This approach allows the development of a simplified depiction of complex systems representative of the multi-perspective lenses used to comprehend the systemic complexity of a problem and provide a clearer picture to analysts and decision makers. This bibliometric meta-analysis of 286 relevant publications in engineering, business, and other social sciences fields explores the historic impacts of SSM on academic research and systems thinking in relevant publications that described or employed SSM for research from 1980-2018. This study produced descriptive narrative outcomes and data visualizations including information about top SSM authors, author citation impacts, common dissemination outlets for SSM work, and other relevant metrics commonly used to measure academic impact. The goal of this piece is to depict who, what, why, when, and where SSM had the greatest impact on research, systems thinking, and methodology after nearly 40 years of use, as we look towards its future as a methodological approach used to comprehend complex problem situations.
\end{abstract}

Keywords: soft systems methodology (SSM); systems thinking; bibliometrics; academic impact of SSM; data visualization

\section{Introduction}

Checkland [1] explained soft systems methodology (SSM) as an approach to understanding complex problem situations one wishes to learn more about and are poorly understood. SSM is a methodology that has shown increasing use over time to address multifaceted business, learning, and engineering problems involving complicated factors and structures about which stakeholders may not agree. The difficulty of translating outcomes from analysis of "messy" or ill-structured problems into usable solutions resulted in some mild criticism of the speed and viability of the SSM process for moving the analytic outcomes into strategic or product improvement recommendations [2]. There is also limited research into the effectiveness of soft systems approaches over time for generating solution, in part because some analysts find the method's requirement of stringent research that requires interactions with stakeholders and complex data sets to be onerous. However, this may be a misguided view because the goal of the approach is often to learn more about a situation, not generate clearly testable solutions. In past attempts, some researchers applied only a portion of the SSM stems in 
their research, which may limit the method's effectiveness [3]. Other criticisms of the method include its slow speed, difficulty in using it with stakeholders during analysis or to implement suggested solutions; further, the complexity of the problems under study may limit its acceptance as a valuable research methodology by some academics or managers [4].

Checkland [5] noted that there are different ways of thinking about systems. Systems are a group of interacting elements or subsystems with a unified goal and defined by its boundary as well as the nature of the internal structure linking its elements (e.g., physical, logical, functional). "Hard systems thinking assumes that the world is a set of systems (i.e. is systemic) and that these can be systematically engineered to achieve objectives. In the soft tradition, the world as it naturally exists is assumed to be problematic; but, it is also assumed that the process of inquiry into the problematic situations that make up the world can be organized as a system" (p. S49-50). "Hard" systems may be considered as organized systems with features and goals upon which stakeholders agree. "Soft" systems often contain identified elements such as outcomes, processes, strategies, or other features about which there is imperfect stakeholder agreement. Further, the system elements may change dynamically in response to local needs as system participants learn new information about their own or external, related systems. However, it is difficult to retain agreement about the best way to organize complex systems permanently, requiring further refinement of agreed upon understanding among participants over time that is generated by continued discourses among participants.

Since early work on SSM by Mingers [6] in the late 1970s and early '80s along with Checkland's groundbreaking 1981 Systems Thinking, Systems Practice book [1] that formalized SSM as a research approach, it has become a means of understanding problems with no single answer for those conducting research in assorted social science fields. SSM is valuable in complex situations that involve multiple stakeholders and systems, especially where learning or making sense of the problem situation is the goal of the study. Other, modified versions of the methodology by Boardman [7] and other authors are used to support visualization of SSM data for the purpose of improving problem situations.

While many students and professors recognize the term "soft systems methodology", SSM's impact on in engineering, business, and other social sciences in the form of vetted, academic research outputs (e.g., peer reviewed articles, committee reviewed dissertations, etc.) is less understood. This leaves additional questions such about the measurable reach of SSM in these academic research areas. Who are the authors using the method to produce research? How extensively is the approach used for research? It is also important to understand where the outcomes of SSM research are published and, using commonly accepted impact scores for associated journals, as a general measure of the degree to which they are perceived to be impactful on academic research and thinking distributed in broadly available publications. Past research by van de Water, Schinkel, and Rozier [8] explored the publications where SSM was published up to 2007, along with an examination of the countries from which the authors and journals were located. Since that time, a significant number of publications have entered public databases, which requires examination of SSM on academic research and dissemination in the ensuing period. A constraint on this research is that many practical applications of SSM used in corporate and other organizational studies that employ SSM are not published. Therefore, their findings are not available for review and remain outside the scope of this study. Such studies are reserved for future research with other, more appropriate methods to that task.

This piece examined the impact of SSM on academic works through a bibliometric meta-analysis of pieces that discussed as an approach or employed SSM for research. We begin with an examination of how systems thinking and the related SSM approach are defined. An exploration of the use of SSM in the fields of business, engineering, and other social sciences then illuminates this research. A bibliometric analysis follows, focused on publications found to discuss or employ SSM to depict the impact of the approach over the last 35 or more years. 


\section{State of Knowledge and Practice}

Current knowledge regarding SSM originated in theory and practice work around General Systems Theory dating back to at least the 1950s and 1960s in a period following World War II, as organizations sought to build complex physical and human systems. Since that time, some authors have built new analytic tools for producing more rapid depictions of SSM analyzed complex, including the conceptagon and Systemigrams [9] in the case of Boardman's [7] version of SSM. The goal of these improvements was to use the better visualizations of the complexity as a means of developing improved systems, whether they are often well-defined manufacturing and software products, or instead, more poorly structured organizational systems upon which agreement about their shape remains elusive or in flux, leading to new problem situations. The following sections review the relevant history of soft systems methodology and its development.

\subsection{General Systems Theory}

Systems thinking, as a term and set of processes, was first introduced and formalized in the 1950s. Originally labeled General Systems Theory (GST), it was developed as both conceptual framework and mathematically expressed theory, most notably by Ludwig Von Bertalanffy [10]. His original conception was that problems identified symptomatically in complex systems across different disciplines affected one another, but they had to be first described independently and then in terms of their interrelations to help researchers clearly understand how they affected one another. While this was only a starting point, GST allowed systems thinking to flourish across disciplines such as ecology [11], engineering [12,13], business and academia [2,12], and education [14]. Furthermore, significant original academic work was done over the last thirty years in multiple disciplines to meaningfully grow the value and use of systems thinking [3,9].

Systems thinking describes the act of examining and seeking to understand a system, an interlinked set of objects, people, actions, and subsystems in a cooperating mechanism or set of activities, as a complex, Gestalt whole [9]. Rather than requiring a person to attempt perception of a multifaceted system one small piece at a time without its inter-relationships; systems thinking seeks to present the entire picture as a means of identifying where different components meet, perform well, or require change. This approach still requires that an analyst shift their gaze from the whole system to the parts in a back-and-forth effort. It is this process that allows comprehension of how components fit together, interact, and depend on one another for the entire system to operate and achieve its overall function. Such holistic thinking permits the mind to discover patterns among each element that may not be immediately evident or emerge over time. This approach requires acknowledging situations surrounding the whole as they change and interact with other, interrelated wholes to create the system as stakeholders are likely to perceive it.

For some authors, systems thinking is synonymous with holistic judgement regarding a coherent phenomenon or conceptual framework. At its core, this systems thinking approach examines the interconnectedness of each part of the system, uncovering patterns regarding how different components work together to produce certain systemic outcomes, as well as what may hinder desired results. The Society for General Systems Research founders stated that systems theory "provide(d) a meta-level language and theory in which the problems of many different disciplines could be expressed and solved" [5]. Unfortunately, GST has not resulted in the substantive investment by scholars to produce a generalized, holistic view across disciplines. Instead, systems thinking expanded slowly over the last 65 or more years in fields such as education, biology, engineering, and increasingly focusing on components of supply, demand, and logistics in the fields of business and related engineering disciplines. 


\subsection{Soft Systems Methodology}

To foster systems thinking about complex organizations and processes, Checkland [15] formalized separate definitions of hard and soft systems, calling his own research approach and related conceptual framework "Soft Systems Methodology" (SSM) [1]. This means of analyzing ill-structured, soft systems emerged from General Systems Theory and includes a seven-stage process for applying SSM. This approach requires the analyst to think both about the real world and the conceptual model of the system under study. The stages include: (1) Entering the unstructured problem situation; (2) expressing the problem situation; (3) formulating root definitions of relevant human activity systems; (4) building conceptual models from the root definitions; (5) comparing models with the real world; (6) defining desirable and feasible changes; and (7) taking action in the problem situation. SSM is a process of generating understanding that may be used by analysts to generate systemic improvement recommendations for a system under study and while it also provides stakeholders with a rich picture of an identified problem situation and related systems one wishes to learn more about. Depending on a researcher's view, the research outcome could be a clearer view of shared systems of knowledge organized by stakeholders, organizational structures, activities, processes, physical objects working in concert, or others, depending on how they are defined at the outset of a study [9].

Checkland [5] explained hard systems research as focused on analyzing well-defined systems with a goal of describing and understanding problem situations in which stakeholder agreement is lacking. Such systems interact with one another and, through examination of the points at which they touch, can be depicted to identify how they may be engineered to perform better. Thus, hard systems analysis is commonly used to seek solutions to a well-defined, agreed upon problem. By comparison, a soft systems research approach is often used to learn more about a poorly defined situation that one seeks to better understand, without necessarily generating testable solutions, though researchers sometimes do so. These soft systems are complex and, when viewed from outside, may be deemed mysterious. While not always the case, when humans are part of the system under study, involve complex cultural mores and multiple systems that interact in uncertain ways with unpredictable outcomes. This challenge stems from the often poorly defined boundaries and conceptual definitions of a system's component parts, subsystems, or complex relations between similarly sized systems. This problem is often because the system emerged and evolved organically in response to its environment and needs, so its form may appear chaotic at the outset of analysis. Since system changes may have been done quickly where acute problems exist, without consideration of the consequence of a decision, there may be many ways for the system to be improved to perform more effectively. Engineers and analysts are meant to inquire into whether the soft system can be organized into what Checkland [15] called a learning system. With a hard systems approach, the Observer sees the world as full of systems that they can engineer; that is, they see the world as systemic. By contrast, in soft systems approaches, the Observer sees the world as full of complexity and confusion. However, these features can be organized for exploration as a learning system, using a systems inquiry process. What is presented here is our understandings of Checkland's concepts resulting from a synthesis of readings. However, Holwell [16] offered historic a critique of many authors' views of SSM, leaving our own open to similar criticism. However, the focus of this research is not our depiction of SSM; rather, we sought to examine the academic impact of the methodology on disseminated literature in social sciences fields. The research methods employed to that end follow in the next section.

\section{Materials and Methods}

This study depicts the impact of soft systems methodology in the engineering, business, and other social research fields. To do so, a multi-strategy, bibliometric analysis [17] was performed on the term "soft systems methodology". This research approach, commonly used in information science studies, involved multiple data sources and analytic approaches. This methodology was deemed appropriate to gather the complex academic evidence available from different sources to help tell the story of the impact of SSM, as evidenced in published research and theory disseminated publicly. 
To meet this goal, a positivist research method and conceptual framing was employed [18] as it was appropriate to our questions, despite SSM being a non-positivistic research methodology. Our numeric, though descriptive approach allowed longitudinal description of the academic use of the methodology, focused on qualities of the academic publications and public metrics. Taking this path allowed us to first observe and visualize the state of use over an extended period with the ability to interpret findings from that observation regarding the subjective impact of SSM generally on academic research outputs. Given SSM's as a qualitative methodology, an interpretivist or hermeneutic research approach may have been in better alignment; however, given the size of the data corpus and scope of each publication, analysis and explanation of hundreds of articles was impractical. Further, such an approach likely would have failed to meet our research goal, which was to provide a historical view of the impact of SSM as a method on academic research as evidenced in published pieces.

This methodology required capturing written pieces that we could directly evaluate for evidence that the pieces included direct discussion of SSM as a methodology, or employed it as a research approach with observable outcomes. Bibliometrics, as a data analytics research methodology, comes from the library and information sciences. It is used to capture quantitative outputs of information sources using descriptive and network statistics based on citations, authors, keywords, texts, and dissemination outlets. In this study, the method was used to identify trends, impacts by use, subjects, and fields that have adopted SSM. Some analyzed data and presented here is meant to provide context for readers less familiar with SSM as a research approach, including who the major authors and journals in the area are. By contrast, other outcomes are valuable for visualization to depict the impacts of published research over time. To hold the rigor of the publication outlets steady for this study, we examined only published pieces we could fully read through to determine whether SSM was discussed or employed for research. Therefore, we did not include conference proceedings, unless they were available for review beyond a short-form abstract. This approach left as our data sources peer-reviewed articles, books, book chapters, white papers, and dissertations/theses. To gather these sources, our data collection methods, which sought to be exhaustive, employed data mining and Boolean searches from multiple sources using the following approach.

\subsection{Data Collection}

Data was gathered from multiple sources to capture the largest possible dataset that met our requirements and build a comprehensive profile of the use of SSM since 1980. The following are the digital tools employed, though not necessarily in order, because finding primary source materials often required using more than one source.

- Harzing's Publish or Perish-This was the initial search tool used to collate the starting dataset. This data mining tool from Google Scholar collects publications based on keywords and produces a listing all articles, books, book chapters, dissertations/theses, white papers, conference proceedings, and reference citations. In addition to authors, titles, and publication names, the tool also provides citation counts and links to the pieces.

- University library databases-JSTOR, ERIC, Web of Science, and others were used in order to gather PDFs of each article for review to determine if SSM was, in fact, present in the publication.

- Research Gate-Many PDFs of SSM pieces were available by their authors for download on this site. Some were freely available, while others were provided upon request.

- Google and Bing searches-Boolean searches were used to find online posted PDFs when they were unavailable elsewhere, as well as to determine whether some mislabeled publications were conference proceedings, books, or chapters, rather than peer-reviewed articles.

- Publisher web sites-Some articles were only available through publishers and purchased, or were sometimes available for no cost.

- Amazon and Google Books-These were used to purchase Kindle or original books as necessary for review. 
- Organization web sites-For those pieces not correctly labeled as conference papers, we gathered abstracts as confirmation that the full paper was available. If not, the piece was not included in the analysis.

- Scimago Institution Rankings-This site includes journal and country scientific indicators drawn from the Scopus database using Google PageRank algorithm to create rankings (called SJR ranks) for each dissemination outlet. When available, the site also includes h-index rankings. Both indices were included in the data corpus to gauge the impact of the journals in which SSM pieces were published. These do not include books, chapters, or most conference proceedings.

The Publish or Perish tool produced 1000 results, limited in the tool to those that included the full keyword terms "soft systems methodology" or "SSM". These pieces were located from the university library databases and other Boolean searches to produce the original corpus of data for review. Each piece was evaluated to ensure that the authors employed a variety of SSM that matched with Checkland, Boardman, or another author that had both described and tested their version in a research setting at least once. However, due to natural variations among authors' approaches that fit their theoretical view or naturalistic setting requirements, we could not hold these constant to say they are all true to a fixed version of SSM. However, each piece claimed to employ or describe a version of SSM they believed met basic criteria aligned to Checkland or another published conception of the approach. All other source outputs were integrated into the database. Using these data sources to build the database, we employed the following approach to analyzing the data to answer our questions as follows.

\subsection{Data Analysis}

To organize, clean, and, analyze or display the collected data, we followed Onwuegbuzie and Teddlie's [19] suggested approach for multi-strategy data analysis, though modified to fit our process that was dictated by our questions and sources, as described below. This included the following steps, though not always in this order because the process was recursive as new data was discovered and refined:

(1). Data transformation and reduction-These two stages were combined in a departure from Onwuegbuzie \& Teddlie's approach because the transformation process was part of the reduction stage. PDFs of publications or hard copies of other texts were reviewed to determine if SSM was discussed or used for research. In the transformation, the qualitative data captured from reviews of the publications was quantized with a binary score of 1 representing the presence of SSM in a piece or 0 if not. Those that did not include SSM were eliminated from the database. Further transformation took place in classification of the pieces from the Publish or Perish mining process when determining if they fit one of the following criteria: (a) peer-reviewed articles, (b) books, (c) book chapters, (d) white papers, (e) dissertations/theses. The publications also had to be available for review, so most conference proceedings were eliminated. Columns with incorrect or irrelevant data (e.g., repeated search dates, publishers, etc.) were also deleted.

(2). Data integration-Research Gate, publisher sites, Scimago ranks, and other data assimilated into the database.

(3). Data comparison and correlation-Data from the different sources was compared and correlated to confirm that each produced the same results and corrections were made, adhering to the source with highest credibility (e.g., primary source). These two stages were combined also differed from Onwuegbuzie and Teddlie's approach because they were concurrently performed. Data that could not be confirmed, such as pieces that were identified as including SSM, but without observable evidence, was eliminated.

(4). Data consolidation-All data was consolidated into the database and primary source texts were organized in a digital folder, organized by subject area. 
(5). Data display-Organized database outcomes were analyzed using the USA version of Microsoft Excel and the accompanying Quick Analysis feature to produce visualizations in the form of tables, charts, and graphs. The outcomes of the data display step are the core of our findings, presented in the next section.

This process allowed us to answer the following questions:

(1). What has been SSM's impact on academic discourses in business, engineering, and other fields since its inception as evidenced by yearly publication trends and journal impact factors?

(2). Where has thinking about SSM been disseminated most often?

(3). What disciplines have been most impacted by SSM?

(4). Who have been the major contributors to the development of SSM?

The cleaned, reduced data produced 286 publications referencing or employing SSM as a research approach and illustrate the impact of SSM on published academic works as a means of depicting its reach.

\section{Discussion}

The findings from our analysis show differing impacts of SSM, depending on field of study. The distribution of articles related to SSM varied considerably since 1980, with certain periods most highly representing its impact. Some authors had more outsized impact on the use of SSM and systems thinking than others. The following sections explore these outcomes with accompanying data visualizations.

\subsection{Impact on Academic Discourses Represented by Publication Trends and Impact Factors}

The first major outcome is the publication trend tied to soft systems methodology from 1980 to 2018 as we approach 40 years of SSM discussion and use. Since this research approach was meant to take a global view of SSM's impact on academic output, we did not discriminate by region, instead choosing to view academic impact as an aggregate, worldwide outcome. Figure 1 presents the number of publications that included some reference to SSM (1980-2018).

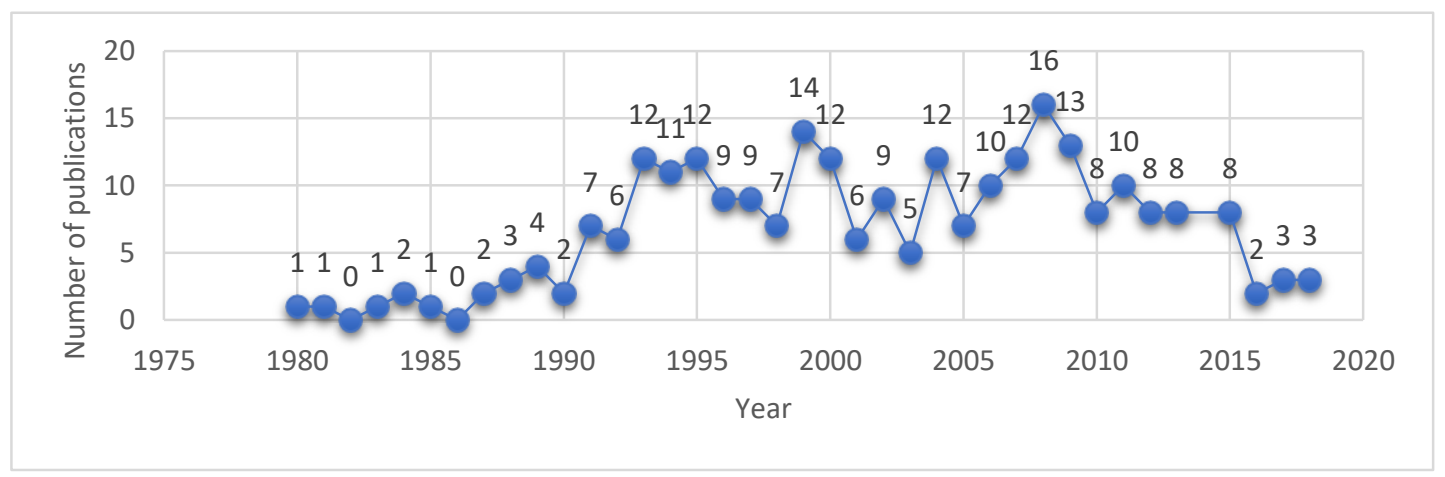

Figure 1. Number of publications by year (1980-2018).

In this figure, we see small growth in the 1980s, with a robust spike in use during the 1990s, following the publication of Checkland's [20] highly cited (569) piece in the Human Systems Management journal as well as Mingers and Taylor's [21] "The use of soft systems methodology in practice". Each piece simplified the process and provided examples that practitioners and theorists could apply. During that time more than 90 publications discussed or applied SSM in practice, showing high interest in the methods that continued through the 2000-2009 period. The period from 1990 to around 2010 included the largest number of SSM-related publications. With the decline in academic publications that employ SSM over the last three years, it is possible that the method may be perceived 
as inappropriate to answering today's research questions, or that they require more rigor than time allows. It may also be that some publications are not yet stored in databases accessible to the authors, so are unrepresented in this dataset. However, for those authors that have invested in the method and find it of value, this decline may be of concern if it is an indication that SSM's value is no longer clear to academic researchers. From an academic impact perspective, the outlets where SSM research and theory are published may also be of concern as noted in the next section.

\subsection{SSM Most Common and Most Impactful Publication Outlets}

While examining the impact of SSM as a function of the number of publication outlets is valuable to show how widely distributed the method is in academia, it is also important to understand where these pieces have been published to get a better sense of how accessible they are. Further, it is important to know the perceived impact of those journals that have been evaluated using objective measures such as SJR and h-index scores to provide a better sense of SSM's academic impact in the social sciences more broadly. The publication outlets that are most highly represented are included in Figure 2.

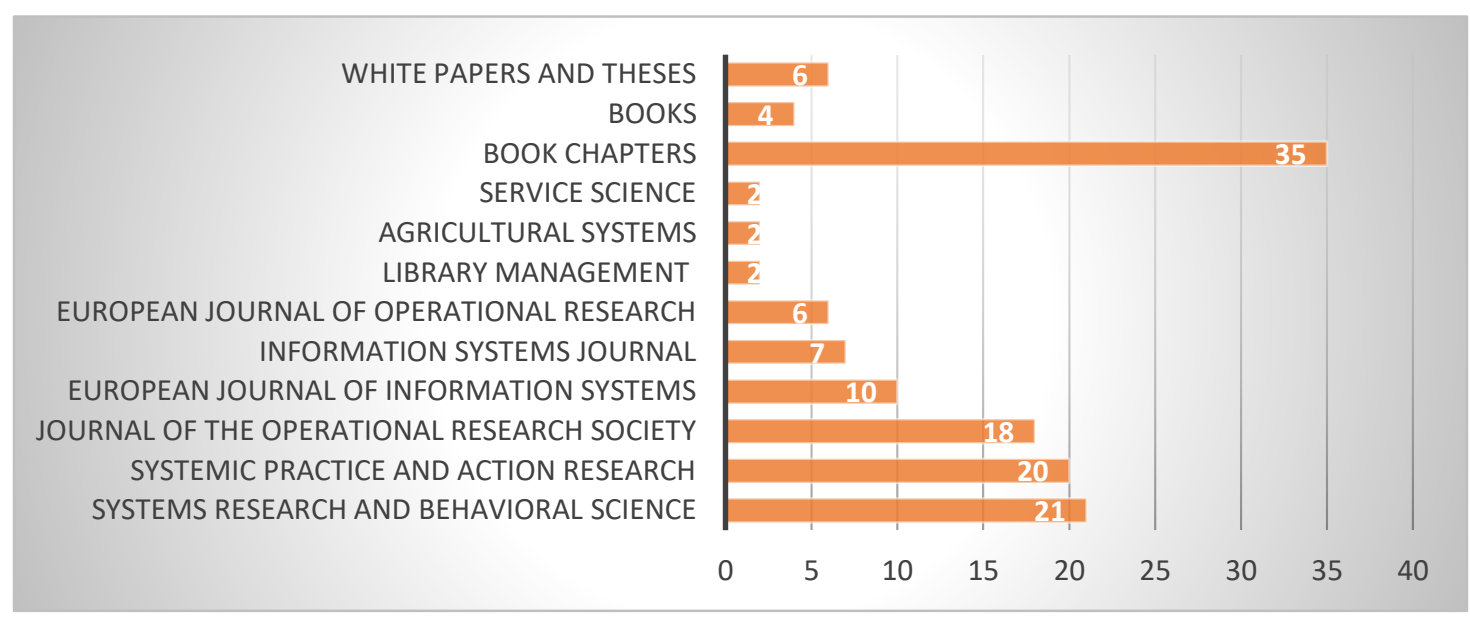

Figure 2. Highest frequency SSM publication outlets.

While the figure does not incorporate citation counts, the largest number of publications related to SSM are book chapters. This is problematic in academia, at least in the USA, because book chapters, like books, are less accessible to researchers that may be impacted by them. Finding and using book chapters as sources requires both knowledge that the edited book exists and a financial investment that many academics today may be unable or unwilling to make. This situation negatively impacts how broadly disseminated the research or theory outcomes are in academia and, in turn, limits the reach of SSM. Five of the top six journals that published SSM pieces are located in Europe, likely increasing knowledge of them and dissemination there. However, given the limitations of access to library databases in the USA due to increasing cost at higher education institutions, it is possible that researchers miss important SSM pieces, since the work is often behind a publisher paywall [22].

The top nine most represented journals each had published at least two SSM pieces, though only eight had citations because two of the pieces in Service Science were recently published. The following Figure 3 shows the citations for the top eight journals.

Systems Research and Behavioral Science was both a top destination for SSM pieces and had the strongest impact on the field based on citation counts. Most pieces in that journal were not research-based according to our analysis; rather, they discussed the development of SSM as an approach to research in a particular discipline. Many articles offered significant adaptations and additions to the methodology to make it easier to use or more applicable in different fields, but failed to report research outcomes from testing those changes. This is an issue noted by Holwell [16] with articles through the 1990s that continues to today. While Systemic Practice and Action Research 
included significant publications, the journal's impact was less evident on the field by citation count, though the number of research studies using SSM was greater than most other journals. However, the most significant publication outlets were not journals, as shown in Table 1.

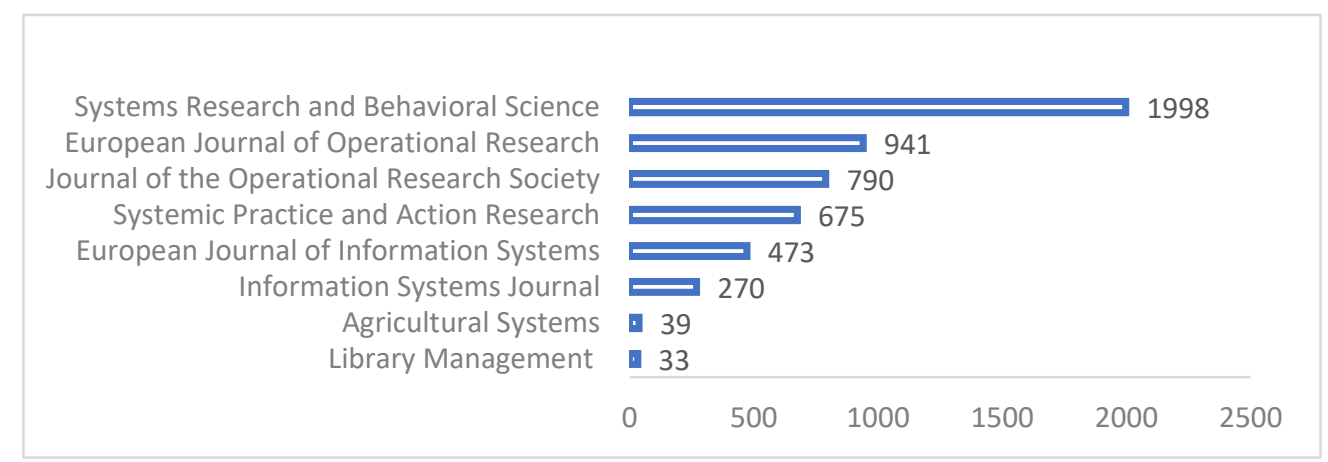

Figure 3. Top eight SSM journal outlets and citations of SSM-related articles.

Table 1. Citation counts for SSM-related publication outlets.

\begin{tabular}{cc}
\hline Dissemination Outlet & Citations \\
\hline Books (66.91\%) & 18,052 \\
\hline Book chapters (13.44\%) & 3625 \\
\hline Systems Research and Behavioral Science (7.41\%) & 1998 \\
\hline European Journal of Operational Research (3.49\%) & 941 \\
\hline Journal of the Operational Research Society (2.93\%) & 790 \\
\hline Systemic Practice and Action Research (2.50\%) & 675 \\
\hline European Journal of Information Systems (1.75\%) & 473 \\
\hline Information Systems Journal (1.00\%) & 270 \\
\hline
\end{tabular}

As mentioned earlier, limited knowledge about and access to books and book chapters reduces dissemination of ideas and research due to cost or marketing of materials, especially from one continent to another. This may negatively impact the reach of SSM in some regions, such as the USA where systems thinking topics tend to be associated with Senge \& Sterman [23], Banathy and Jenlink [14], Reigeluth [24], or other authors that more commonly publish conceptual or "thought pieces" rather than research outcomes. With the heavy focus on positivist, numbers-driven research methods in the USA, it is possible that American academics' exposure to systems thinking from these sources has provided a limited picture of SSM and related methods. They may therefore view such approaches as less rigorous and, therefore, less valuable. This situation may account for the difference in where SSM pieces have been published as well, with European journals significantly more represented than in USA journals. This condition could indicate either an implicit or explicit bias among journal editors and researchers against soft research methods, and qualitative approaches more broadly, in different fields that must be overcome with better teaching and training [25].

For SSM as a topic of discourse and use as a research method, Figure 4 visualizes the high impact of four books and thirty-five book chapters had versus journals. 11,144 total book citations came from Checkland's and Scholes' 1990 book [26], which gave that publication the largest impact on other authors. Removing that text as an outlier, SSM-related books still had almost twice the citation impact of book chapters and nearly a treble impact over the top journal's pieces, limiting the impact of academic research pieces that employed SSM by comparison. 


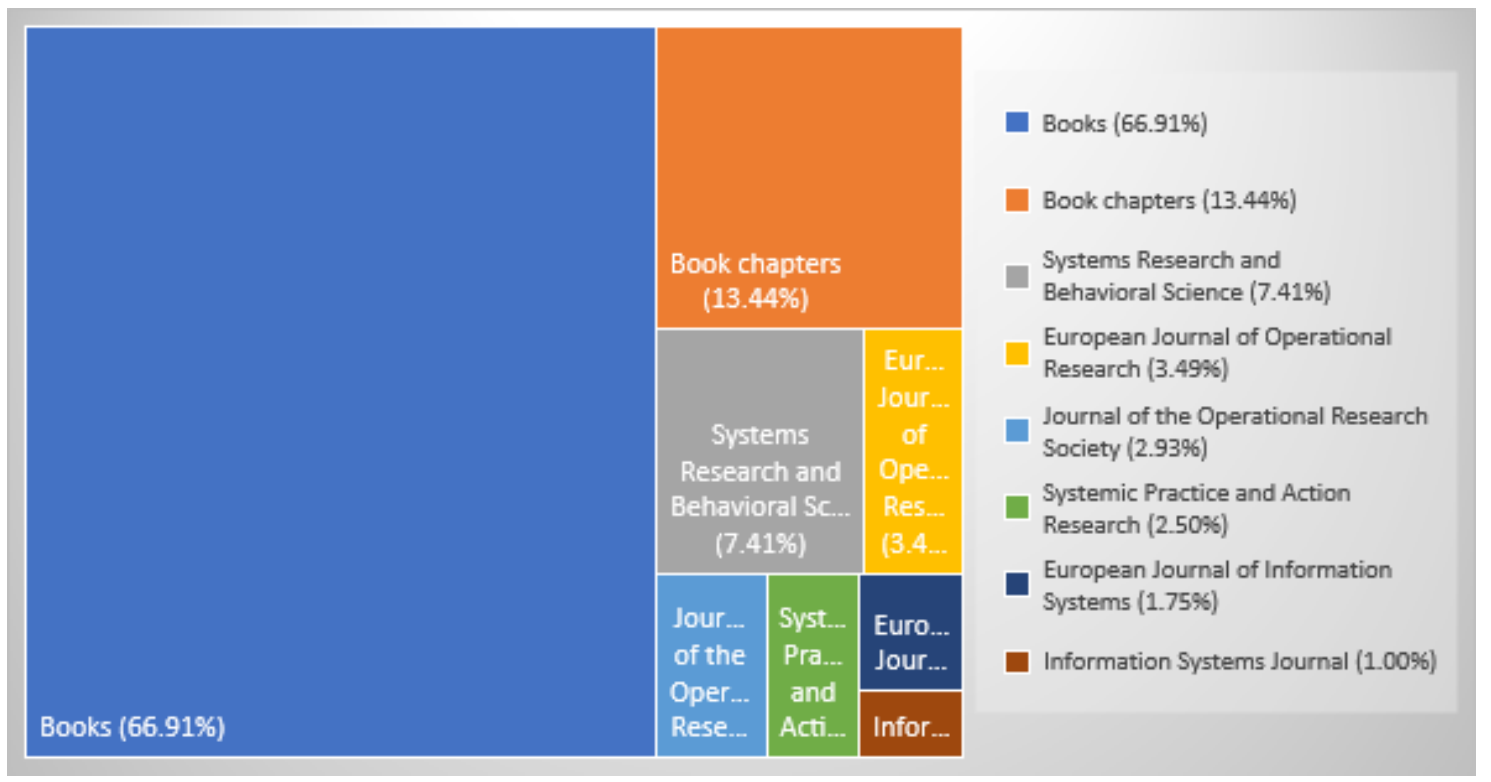

Figure 4. Citation impact of SSM dissemination outlets as a percentage of all citation.

Based on citation counts, books had the largest percentage impact by a significant margin, with book chapters following substantially lower. Chapters and books combined accounted for $80.35 \%$ of all measured SSM citation impact, the top journals accounting for only $19.08 \%$. This means all other journals accounted for only $0.57 \%$ of all citation impact, which limits perception that the SSM work contained in them reached an interested audience, which may be partly responsible for the decline of published academic pieces that employ SSM in recent years. This differs by field, with some disciplines such as engineering and business showing historically stronger affinity with SSM methods than others. Findings regarding the disciplines impacted by publications containing information about or research using SSM are included in the next section.

\subsection{Disciplines Most Impacted by SSM}

To capture which disciplines are most impacted by SSM, each publication was reviewed and coded according to the Scimago journal subject area that most closely aligned with the content. While white papers, dissertations, books, and chapters do not have subject areas, those were coded in accordance with similarity to journal articles containing the same subject matter. Figure 5 presents the distribution of articles according to coding for Scimago subject area.

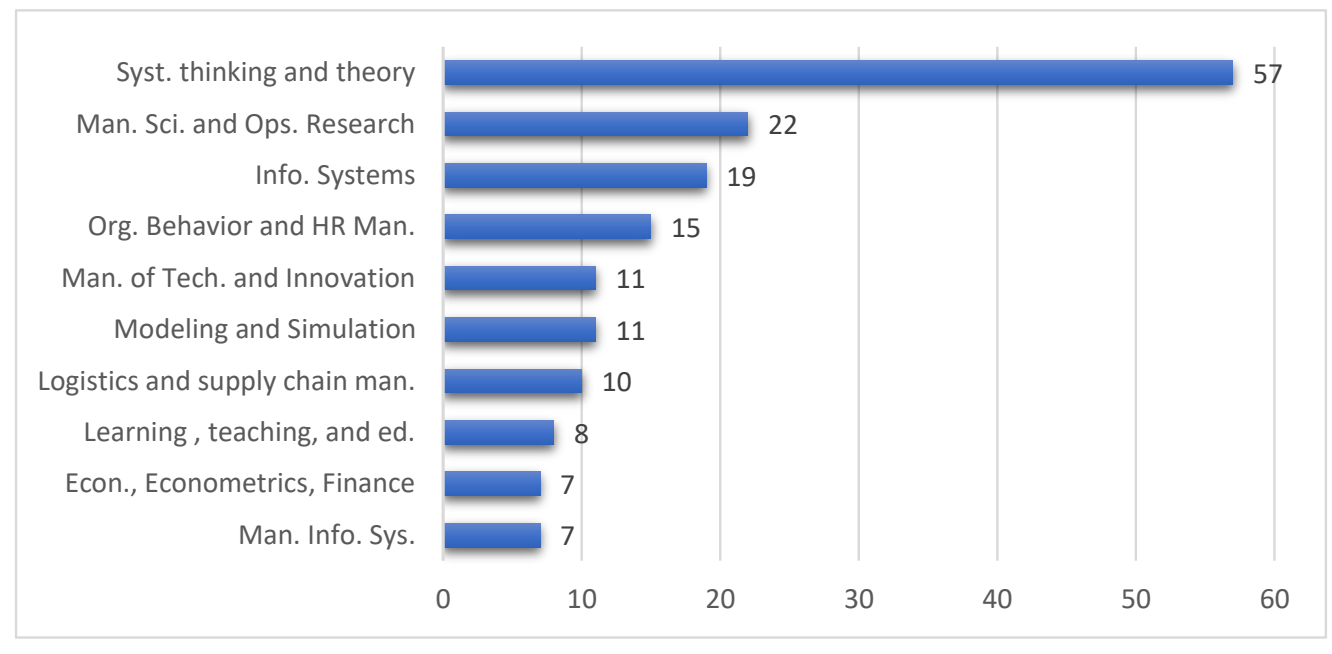

Figure 5. Top 10 SJR coded subjects of publications using SSM. 
"Systems thinking and systems theory" constituted the largest subject, with "Management science and operations management" trailing considerably. This was, in part, because our content analysis revealed that most pieces coded as systems thinking and systems theory discussed the development of SSM from the perspective of a discipline, but often contained no research application. Most also only described proposed alterations of the methodology for a particular purpose [27] (e.g., software development by adding UML) or a description of SSM to a new audience [28,29] (e.g., marketing, medical settings, etc.) and failed to provide evidence of their effectiveness. The Scimago codes above were classified into broad subject categories based on the topics of the articles in the database and are presented in Figure 6.

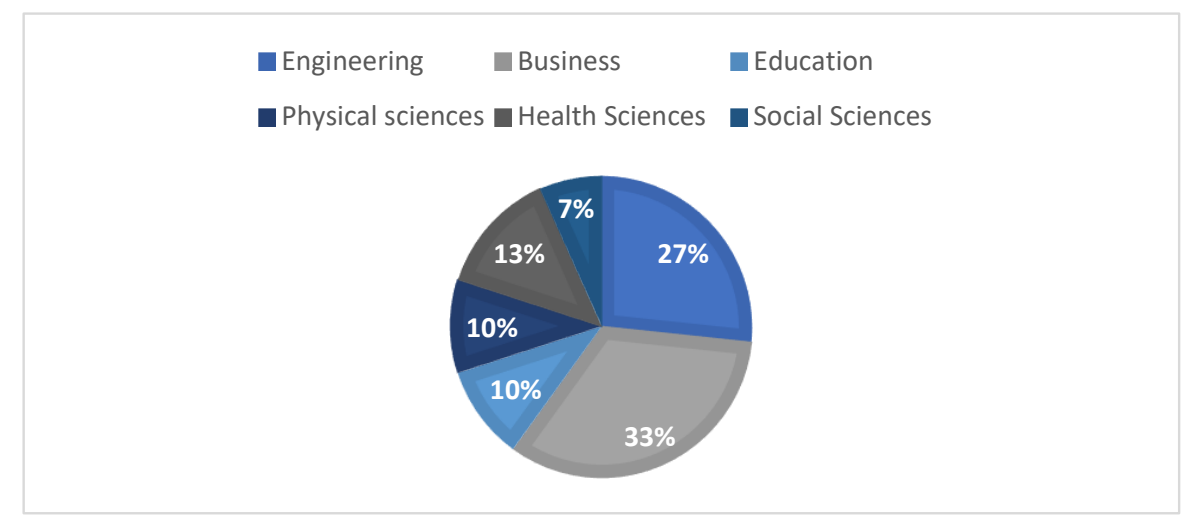

Figure 6. Disciplinary category representation of SSM-related articles.

Business was the largest discipline impacted by SSM research in publications from 1980-2018 with ten subjects represented. Engineering followed with eight highly coded Scimago subjects. Physical science category pieces tended to focus on large scale, messy problems like water allocation in countries with poor access to clean drinking water, making SSM an appropriate tool for research. Education and health sciences also had ill-defined problems that made SSM useful for studying complex systems and, while SSM was less impactful than with business or engineering, there was some influence. The authors that contributed to these pieces had differential impacts on SSM research and practice, as shown in the following section.

\subsection{Major Contributors to SSM Theory and Research}

As measured by the number of publications tied to SSM, twelve had the highest impact. These are presented in Figure 7, showing the percentage of the 286 SSM-related publications analyzed here that they are responsible for as an author since 1980. Each had three or more publications related to SSM.

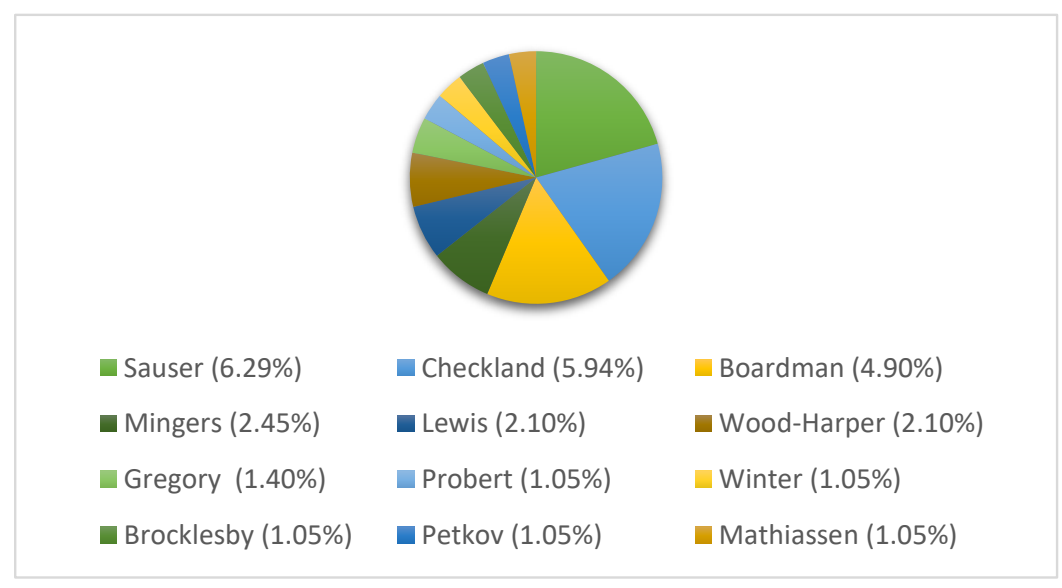

Figure 7. Top author representation among all SSM-related publications. 
The top six authors combine to represent $23.78 \%$, or nearly a quarter of all SSM-related publications since 1981. The remaining $75 \%$ of pieces written by other authors indicates a broad distribution of the ideas and application of SSM, with those above serving as what Lave and Wenger [30] called core participants in what may be considered Community of Practice centered on the development and use of soft systems methodology for academic research and theory development. While the distribution of the work is fairly broad, the following Figure 8 shows that the citation impact is substantially different.

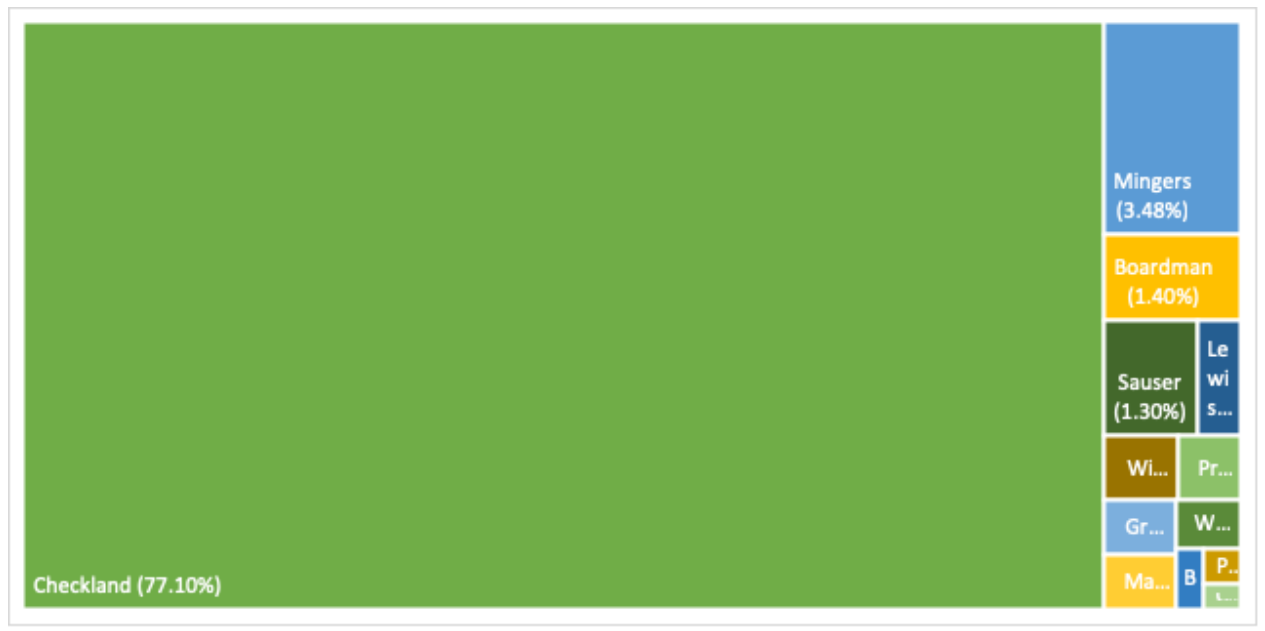

Figure 8. Author impact on field by citation representation percentage.

Checkland's impact, as expected, is clearly massive, regardless of the field of influence. His work on SSM garnered 23,780 citations, with 11,114 alone for his 1981 book. Mingers contributed substantial work as well. Boardman, with his variant of SSM applied in engineering and business settings, and his work with Sauser, showed strong impacts among the remaining authors. However, with less than $23 \%$ of all citations coming from authors besides Checkland, the academic impact distribution of SSM as a research approach did not have the reach that its proponents may have hoped.

\section{Conclusions}

Since Checkland synthesized a coherent set of steps for soft systems methodology and Boardman developed his revised approach later, SSM has continued to evolve to address perceived challenges and new means of applying the principles in diverse disciplines. Boardman's significant contribution to the methodology and books on systems thinking significantly contributed to the expansion of use of SSM through his own version, commonly referred to as BSSM. His work to expand SSM into business and other disciplines is correlated with the major expansion of use of systemic diagrams as outcomes in research publications between 1993 and 2015. While the database search for SSM resulted in more than 32,000 citations, other soft research methods such as failure modes and effects analysis $(228,524)$ and system dynamics $(2,380,988)$ showed more impact by that measure. To grow the thinking about and use of SSM, we offer four propositions for improvement to soft systems methodology training and process.

- Improved university education

In Europe, where many of SSM's principles emerged and were formalized into method, graduate programs tend to teach it alongside the mathematically driven, positivist methods (e.g., linear algebra, regression analysis, etc.) common in USA business schools. However, outside of the books and articles that lay out the steps for SSM, limited formal training to use SSM currently exists in the USA outside of doctoral programs (e.g., Stevens Point, North Texas) that include faculty who have themselves received training. This is not an efficient means of transferring knowledge about how to employ the 
methodology in different contexts, relying as it does mainly on cognitive apprenticeship and where one chooses to attend university.

- $\quad$ Training using public media outside of academia

Improved training and knowledge sharing could also be accomplished through the development of publicly available online training videos with activities, massive open online courses or similar pedagogical approaches to further disseminate the methods and train a broader array of researchers. Doing so could increase awareness, ability to appropriately employ, and overall acceptance of SSM across disciplines. We believe standardized, broadly available training would add value to researchers and organizational leaders who want to understand how using SSM can benefit them. Such training could increase the overall number of users who employ SSM to understand their complex problem situations, also increasing the academic impact and acceptance of the approach.

- More SSM-based research published in diverse field journals

Exposure of academics to SSM research outcomes through publication of articles in journals outside of business and engineering fields is also important to increase the perception that it is a valuable tool for social science research. The more often researchers see academic outcomes that can be used to solve problems in a variety of fields, the more likely we believe they will be to use them. With significant examples of application, acceptance of both method and findings should increase.

- Increase the diversity of authors using SSM for academic research

For a research methodology and related concepts to take hold in academia, it must be taught broadly, used regularly, and accepted by editors and reviewers alike. However, it must also be used by a significant number of authors, rather than just a small group of about ten core participants noted earlier who are responsible for much of the academic discourse around SSM, or it will not grow. To improve this situation will require mentoring and discussion from these core participants at conferences, willingness to review for journals that publish SSM research, and supportive feedback in coursework and theses produced with the methods. However, this is an important part of the collegiality and social construction of knowledge central to the academic mission.

The findings reported in this article have several limitations; however, it is intended to start new conversations about how to grow SSM as a robust methodology in academia in the future. Because all research is imperfect due to incomplete information available at any time due to access (e.g., limited article database access, books out of print, etc.) and author cognition (e.g., lack of knowledge about sources, distance from alternate sources, etc.), we are likely to have missed some publication that one reader or another may find foundational. However, the sample of data in the corpus presented here indicates that SSM as a methodology had some significant impact on academic thinking in the USA and Europe from 1980-2018. While SSM provided strong value in the past and has the potential for greater impact across many disciplines in the future, increasing its use and acceptance in academic disciplines requires change. Modifications to practice and thinking about SSM should take place in university education, academic publishing, and in conference discourses to help foster improved researcher attitudes towards non-positivistic research methods in engineering, business, and other fields. Future SSM research outcomes can better explain the value of the methodology to those that would benefit from it in academia and be a means for growing field-specific knowledge regarding complex problem situations.

Author Contributions: Conceptualization: S.W. and B.S.; methodology: S.W.; validation: B.S. and D.N.; formal analysis: S.W.; investigation: S.W.; resources: S.W., B.S., and D.N.; data curation: S.W.; writing一original draft preparation: S.W.; writing—review and editing: S.W., B.S., and D.N.; visualization: S.W.; supervision, B.S.

Funding: This research received no external funding.

Conflicts of Interest: The authors declare no conflict of interest. 


\section{References}

1. Checkland, P. Systems Thinking, Systems Practice; Wiley \& Sons: New York, NY, USA, 1981.

2. Mingers, J.; White, L. A review of the recent contribution of systems thinking to operational research and management science. Eur. J. Oper. Res. 2010, 207, 1147-1161. [CrossRef]

3. Mingers, J. Soft OR comes of age-but not everywhere! Omega 2011, 39, 729-741. [CrossRef]

4. Houghton, L.; Ledington, P.W.J. The Evolution of Confusion: Soft Systems Methodology and Social Theory Revisited. Australas. J. Inf. Syst. 2002, 9, 75-83. [CrossRef]

5. Checkland, P. Soft systems methodology: A thirty year retrospective. Syst. Res. Behav. Sci. 2000, 17, S11-S58. [CrossRef]

6. Mingers, J. Towards an appropriate social theory for applied systems thinking-Critical theory and soft systems methodology. J. Appl. Syst. Anal. 1980, 7, 41-49.

7. Boardman, J.T. Process model for unifying systems engineering and project management. Eng. Manag. 1994, 4, 25-35. [CrossRef]

8. Van De Water, H.; Schinkel, M.; Rozier, R. Fields of application of SSM: A categorization of publications. J. Oper. Res. Soc. 2007, 58, 271-287. [CrossRef]

9. Boardman, J.; Sauser, B. Systems Thinking: Coping with 21st Century Problems, 1st ed.; CRC Press: Boca Raton, FL, USA, 2008.

10. Von Bertalanffy, L. An outline of general system theory. Br. J. Philos. Sci. 1950, 1, 134-165. [CrossRef]

11. Bronfenbrenner, U. The Experimental Ecology of Education. Educ. Res. 1976, 5, 5-15. [CrossRef]

12. Caws, P. General Systems Theory: Its Past and Potential. Syst. Res. Behav. Sci. 2015, 32, 514-521. [CrossRef]

13. François, C. Systemics and Cybernetics in a Historical Perspective. Syst. Res. Behav. Sci. 1999, 16, $203-219$. [CrossRef]

14. Banathy, B.H.; Jenlink, P.M. Systems inquiry and its application in education. In Handbook of Research for Educational Communications and Technology; Routledge: London, UK, 2003; pp. 37-58.

15. Checkland, P. Achieving 'desirable and feasible' change: An application of soft systems methodology. J. Oper. Res. Soc. 1985, 36, 821-831.

16. Holwell, S. Soft Systems Methodology: Other Voices. Syst. Pract. Action Res. 2000, 13, 773-797. [CrossRef]

17. Robson, C.; McCartan, K. Real World Research, 4th ed.; John Wiley \& Sons: Chichester, West Sussex, UK, 2016.

18. Rosenberg, A. Philosophy of Social Science, 5th ed.; Westview Press: New York, NY, USA, 2015.

19. Onwuegbuzie, A.J.; Teddlie, C. A framework for analyzing data in mixed methods research. In $S A G E$ Handbook of Mixed methods in Social \& Behavioral Research, 1st ed.; Tashakkori, A., Teddlie, C., Eds.; Sage: Thousand Oaks, CA, USA, 2003; pp. 351-383.

20. Checkland, P.B. Soft Systems Methodology. Hum. Syst. Manag. 1989, 8, 273-289.

21. Mingers, J.; Taylor, S. The Use of Soft Systems Methodology in Practice. J. Oper. Res. Soc. 1992, 43, 321-332. [CrossRef]

22. Kleyn, L.; Rosemary Nicholson, D. The Cost of Accessing Academic Research is Way too High. This must Change. The Conversation. 2018. Available online: http://theconversation.com/the-cost-of-accessingacademic-research-is-way-too-high-this-must-change-105583 (accessed on 4 February 2019).

23. Senge, P.M.; Sterman, J.D. Systems thinking and organizational learning: Acting locally and thinking globally in the organization of the future. Eur. J. Oper. Res. 1992, 59, 137-150. [CrossRef]

24. Reigeluth, C.M. The imperative for systemic change. Syst. Chang. Educ. 1994, 32, 3-11.

25. Roulston, K.; Shelton, S.A. Reconceptualizing Bias in Teaching Qualitative Research Methods. Qual. Inq. 2015, 21. [CrossRef]

26. Checkland, P.; Scholes, J. Soft Systems Methodology in Action; Wiley: Chichester, West Sussex, UK, 1990.

27. Cloutier, R.; Sauser, B.; Bone, M.; Taylor, A. Transitioning systems thinking to model-based systems engineering: Systemigrams to SysML models. IEEE Trans. Syst. Man Cybern. Syst. 2015, 45, 662-674. [CrossRef]

28. Driver, J.; Louvieris, P. POSIT-ively soft systems methodology for marketing. Eur. J. Mark. 1998, 32, 419-440. [CrossRef] 
29. Braithwaite, J.; Hindle, D.; Iedema, R.; Westbrook, J.I. Introducing soft systems methodology plus (SSM+): Why we need it and what it can contribute. Aust. Health Rev. 2002, 25, 191-198. [CrossRef] [PubMed]

30. Lave, J.; Wenger, E. Situated Learning: Legitimate Peripheral Participation; Cambridge University Press: Cambridge, UK, 1991; Volume 95. 